\title{
Influence of Co Doping on Crystal and Magnetic Properties of $\mathrm{Gd}_{2} \mathrm{Cu}_{2} \mathrm{In}$
}

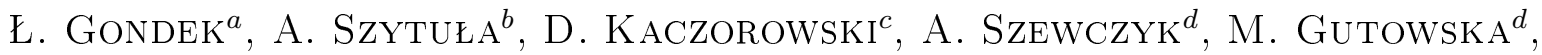 \\ YU. TYVANCHUK ${ }^{e}$ AND YA.M. KALYCHAK ${ }^{e}$ \\ ${ }^{a}$ Faculty of Physics and Applied Computer Science, AGH University of Science and Technology \\ al. A. Mickiewicza 30, 30-059 Kraków, Poland \\ ${ }^{b}$ M. Smoluchowski Institute of Physics, Jagiellonian University, W.S. Reymonta 4, 30-059 Kraków, Poland \\ ${ }^{c} \mathrm{~W}$. Trzebiatowski Institute of Low Temperature and Structure Research, Polish Academy of Sciences \\ P.O. Box 1410, 50-950 Wrocław, Poland \\ ${ }^{d}$ Institute of Physics, Polish Academy of Sciences, al. Lotników 32/46, 02-668 Warszawa, Poland \\ ${ }^{e}$ Department of Inorganic Chemistry, Ivan Franko National University of Lviv \\ Kyryla i Metodiya 6, UA-79005 Lviv, Ukraine
}

(Received February 7, 2012)

\begin{abstract}
Physical properties of $\mathrm{Gd}_{2} \mathrm{Cu}_{2-x} \mathrm{Co}_{x} \operatorname{In}(x=0.1,0.2,0.3)$ samples are investigated. The paper brings results of X-ray diffraction, magnetometric as well as specific heat studies. It was found that only sample with $x=0.1$ exhibits desired crystal structure. Other compositions show existence of impurities due to lack of dissolution Co atoms. For $\mathrm{Gd}_{2} \mathrm{Cu}_{1.9} \mathrm{Co}_{0.1} \mathrm{In}$ sample the Curie temperature of $92.5 \mathrm{~K}$ was evidenced. Thus, an enhancement of ferromagnetic correlations with comparison to $\mathrm{Gd}_{2} \mathrm{Cu}_{2} \mathrm{In}$ sample was evidenced. It was found that $\mathrm{Gd}_{2} \mathrm{Cu}_{1.9} \mathrm{Co}_{0.1}$ In sample exhibits magnetocaloric effect within broad temperature range.
\end{abstract}

PACS: $75.30 .-\mathrm{m}, 75.30 . \mathrm{Kz}, 75.50 . \mathrm{Ee}$

\section{Introduction}

$\mathrm{R}_{2} \mathrm{~T}_{2} \mathrm{In}$ compounds, where $\mathrm{R}$ is rare earth and $\mathrm{T}$ is $d$-electron metal, crystallise within tetragonal $\mathrm{Mo}_{2} \mathrm{FeB}_{2}$ crystal structure [1]. Crystal structure parameters as well as basic magnetic properties of $\mathrm{R}_{2} \mathrm{Cu}_{2}$ In family were reported in the literature [2-6]. Most samples of this family exhibit ferromagnetic ordering, except $\mathrm{Ce}_{2} \mathrm{Cu}_{2} \mathrm{In}$. The Curie temperatures of Gd, Tb, Dy, Ho, Er and Tm-based compounds are equal to 85.5, 81.0, 45.5, 26.7, 37.0 , and $29.5 \mathrm{~K}$, respectively [5]. On the other hand, the $\mathrm{Ce}_{2} \mathrm{Cu}_{2} \mathrm{In}$ is an antiferromagnet with ordering temperature of $5.5 \mathrm{~K}$ [3]. For $\mathrm{Yb}_{2} \mathrm{Cu}_{2} \mathrm{In}$ sample no magnetic ordering down to $2 \mathrm{~K}$ was reported yielding divalent state of $\mathrm{Yb}$ [6]. This conclusion was supported by observation of significantly higher lattice constants that for closely lying Tm or Lu-based compounds [6].

In this work an influence of Co doping on physical properties of $\mathrm{Gd}_{2} \mathrm{Cu}_{2} \mathrm{In}$ sample is reported. To our best knowledge, the $\mathrm{Gd}_{2} \mathrm{Co}_{2}$ In compound does not exist. Thus, only limited Co doping may be introduced.

\section{Experimental}

Polycrystalline samples of $\mathrm{Gd}_{2} \mathrm{Cu}_{2-x} \mathrm{Co}_{x} \mathrm{In}(x=0.1$, $0.2,0.3)$ stoichiometry were prepared by arc melting of high-purity elements (Gd: $3 \mathrm{~N} ; \mathrm{Cu}$ and $\mathrm{Co}: 4 \mathrm{~N} ; \mathrm{Ge}: 5 \mathrm{~N}$ ) in a titanium-gettered argon atmosphere. The buttons were remelted several times in order to ensure good homogeneity. The resulting ingots were annealed in evacuated quartz capsules at $600^{\circ} \mathrm{C}$ for 1 week.
X-ray powder diffraction patterns were collected on Siemens D5000 diffractometer using $\mathrm{Cu} K_{\alpha}$ radiation. The X-ray diffraction (XRD) measurements were performed down to $74 \mathrm{~K}$ using the Oxford Instruments cryostat.

The magnetic properties were studied in the $1.7-400 \mathrm{~K}$ temperature range and in external magnetic fields up to $5 \mathrm{~T}$ employing a commercial SQUID magnetometer (Quantum Design MPMS-5).

Specific heat studies were carried out by the relaxation method using the Quantum Design PPMS-9 platform. These measurements were made in the $1.9-300 \mathrm{~K}$ temperature range.

\section{Results and discussion}

\subsection{Crystal structure}

$\mathrm{Gd}_{2} \mathrm{Cu}_{1.9} \mathrm{Co}_{0.1} \mathrm{In}$ sample crystallises within the $\mathrm{Mo}_{2} \mathrm{FeB}_{2}$ (space group P4/mbm No. 127) crystal structure. X-ray diffraction patterns at $300 \mathrm{~K}$ are presented in Fig. 1. All reflections can be indexed within original space group, thus the sample does not exhibit any impurities. This result suggests that Co atoms are entirely incorporated within $\mathrm{Cu}$ sublattice. For samples with $x=0.2$ and $x=0.3$ the $\mathrm{GdCu}_{2} \mathrm{In}$ impurity phase was detected yielding a lack of further Co dissolution possibility (see Fig. 1). For $x=0.1$ the lattice constants are $a=7.51728(37) \AA$ and $c=3.80314(22) \AA$, the parameters are very close to those reported for $\mathrm{Gd}_{2} \mathrm{Cu}_{2} \mathrm{In}$ 


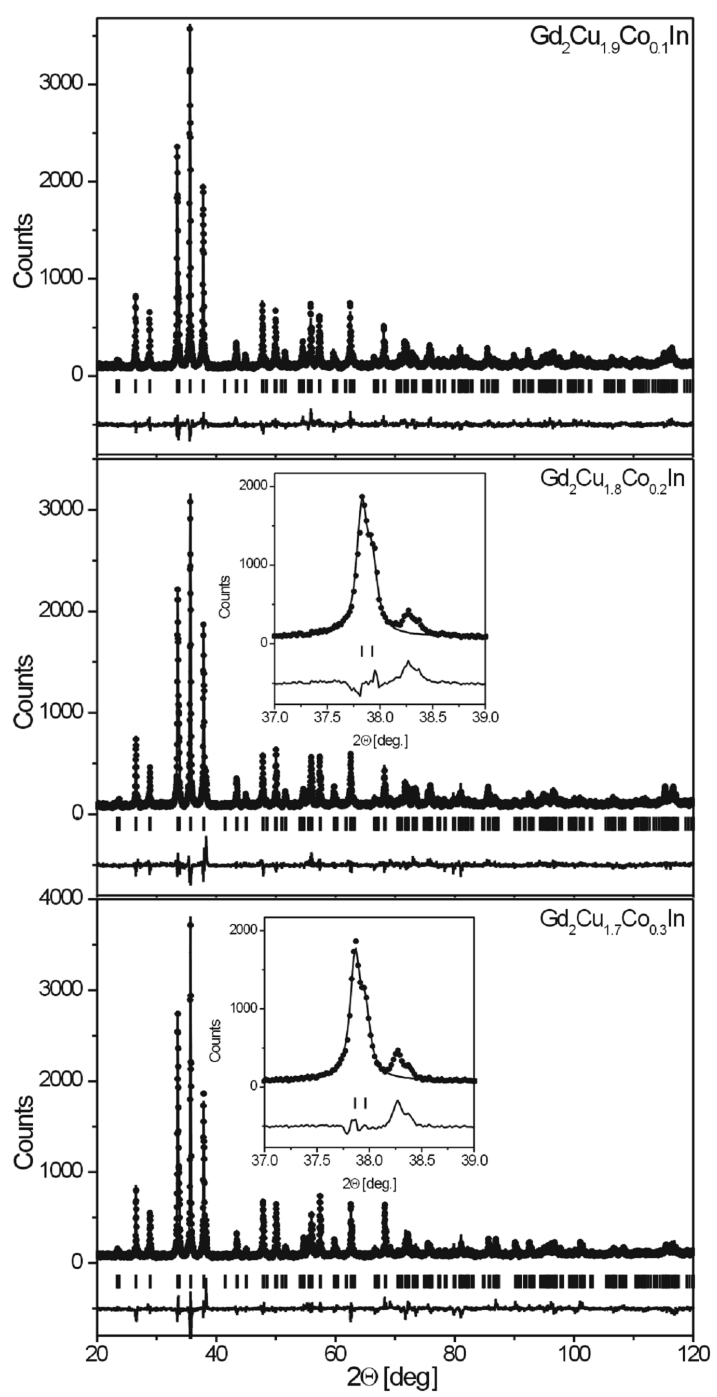

Fig. 1. X-rays diffraction patterns of $\mathrm{Gd}_{2} \mathrm{Cu}_{2-x} \mathrm{Co}_{x} \mathrm{In}$ taken at $300 \mathrm{~K}$. For samples with $x=0.2$ and 0.3 main impurity reflection of $\mathrm{GdCu}_{2} \mathrm{In}$ is presented in insets.

sample [1]. This is consistent with small difference between metallic radii of $\mathrm{Cu}$ and $\mathrm{Co}$ atoms.

On the other hand, the following lattice constants were found for sample with $x=0.2$, where $a=7.51440(35) \AA$ and $c=3.80277(20) \AA$ and with $x=0.3$, where $a=$ $7.50759(43) \AA$ and $c=3.80103(26) \AA$. Lattice parameters for samples with $x>0.1$ are significantly lower in comparison to $\mathrm{Gd}_{2} \mathrm{Cu}_{1.9} \mathrm{Co}_{0.1} \mathrm{In}$. This is connected with non-stoichiometric composition of the $x=0.2$ and 0.3 samples, where $\mathrm{Co}$ ions do not occupy the $\mathrm{Cu}$ sites only. They are introduced into the $\mathrm{Gd}$ and the In positions as well, resulting in formation of the $\mathrm{GdCu}_{2} \mathrm{In}$ impurity phase. Thus, physical properties of samples with $x=0.2$ and 0.3 were not an object of further studies.

For the $\mathrm{Gd}_{2} \mathrm{Cu}_{1.9} \mathrm{Co}_{0.1}$ In the XRD measurements were performed within $74-300 \mathrm{~K}$ temperature range. The temperature dependences of the lattice constants as well as the unit cell volume are presented in Fig. 2. An anoma- lous behaviour of those parameters at low temperatures was evidenced. Namely, significant jump of the $a$ lattice constant at the $95 \mathrm{~K}$ is visible. At this temperature the $c$ lattice constant behaves similarly, however the corresponding change of its value is not so spectacular. An additional, smaller anomaly at $83 \mathrm{~K}$ for the $c$ parameter is visible as well. The unit cell volume exhibits discontinuity just at $95 \mathrm{~K}$, which is clearly connected with the ferromagnetic ordering of the sample (see further paragraphs).
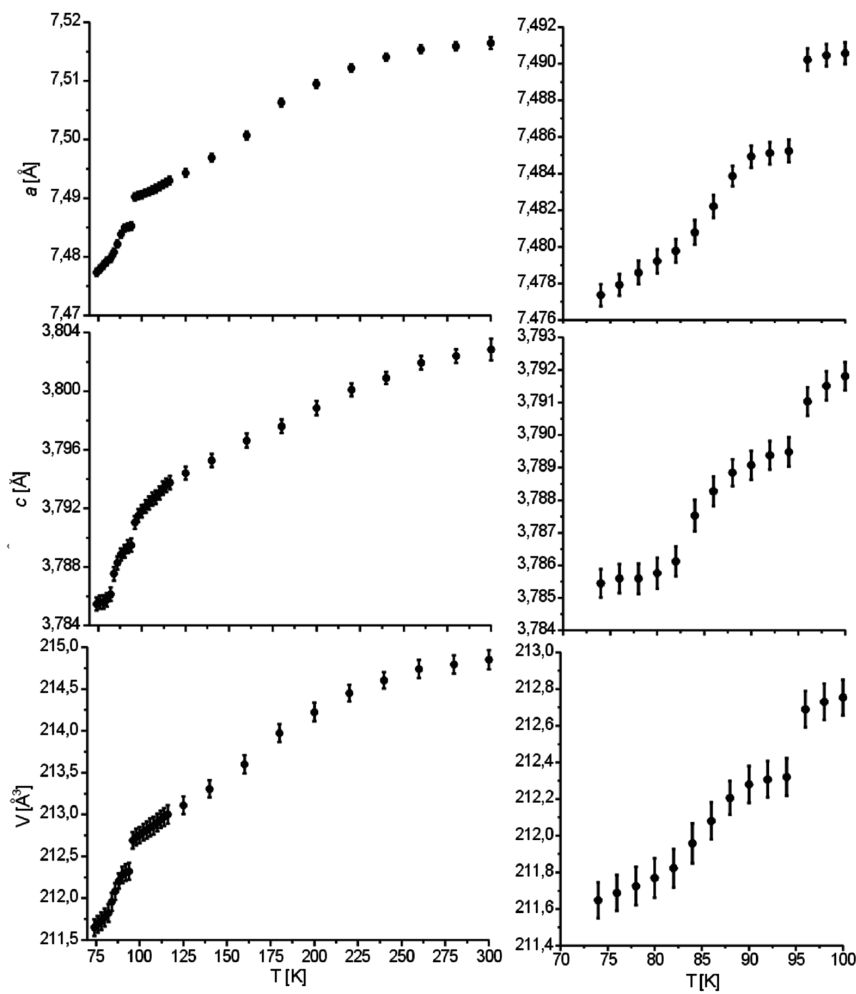

Fig. 2. Temperature variation of the lattice constants as well as the unit cell volume of $\mathrm{Gd}_{2} \mathrm{Cu}_{1.9} \mathrm{Co}_{0.1} \mathrm{In}$. The left parts show full-range data, whereas the right ones just low-temperatures range.

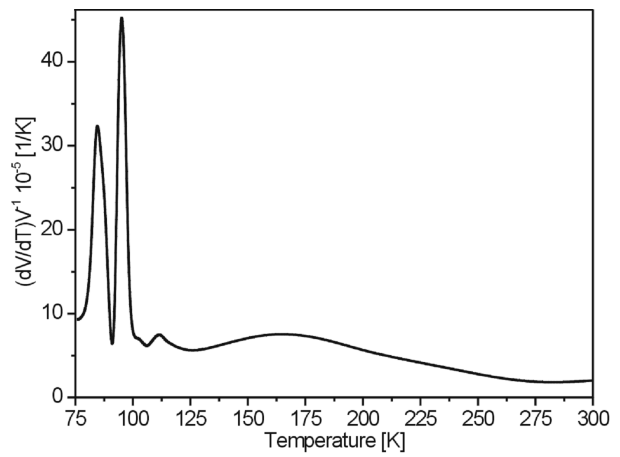

Fig. 3. Volume expansion coefficient versus temperature of $\mathrm{Gd}_{2} \mathrm{Cu}_{1.9} \mathrm{Co}_{0.1} \mathrm{In}$. 
In Fig. 3 the calculated temperature volume expansion coefficient is presented. The coefficient was calculated as $\frac{1}{V} \frac{\mathrm{d} V}{\mathrm{~d} T}$ and its value at the room temperature is close to $2.5 \times 10^{-5} 1 / \mathrm{K}$. At 83 and $95 \mathrm{~K}$ two distinct anomalies are visible. The latter corresponds to magnetic ordering of the sample.

\subsection{Magnetic properties}

Magnetic measurements indicate that the $\mathrm{Gd}_{2} \mathrm{Cu}_{1.9} \mathrm{Co}_{0.1}$ In orders ferromagnetically below $94 \mathrm{~K}$, where the zero-field cooling (ZFC) and field-cooling (FC) magnetisations exhibit a sudden rise (see inset to Fig. 4). Inverse magnetic susceptibility exhibits linear behaviour above temperature of roughly $130 \mathrm{~K}$. Fitted Curie-Weiss formula yields the effective magnetic moment of $8.06(1) \mu_{\mathrm{B}}$ and the paramagnetic Curie temperature $\theta_{\mathrm{p}}$ of $101.6(3) \mathrm{K}$. The effective magnetic moment is close to the free $\mathrm{Gd}^{3+}$ ion value $\left(7.94 \mu_{\mathrm{B}}\right)$. Positive paramagnetic Curie temperature indicates ferromagnetic interaction between $\mathrm{Gd}$ ions. The ordering temperature as well as $\theta_{\mathrm{p}}$ is enhanced in comparison to values reported for $\mathrm{Gd}_{2} \mathrm{Cu}_{2} \mathrm{In}$ sample $(85.5 \mathrm{~K}$ and $90.0 \mathrm{~K}$, respectively [5]). Isothermal magnetisation curve is typical of ferromagnetic material with saturation magnetic moment of $7.13 \mu_{\mathrm{B}}$ per $\mathrm{Gd}$ ion (see inset to Fig. 4); that value is very close to this reported for $\mathrm{Gd}_{2} \mathrm{Cu}_{2} \mathrm{In}[5]$.

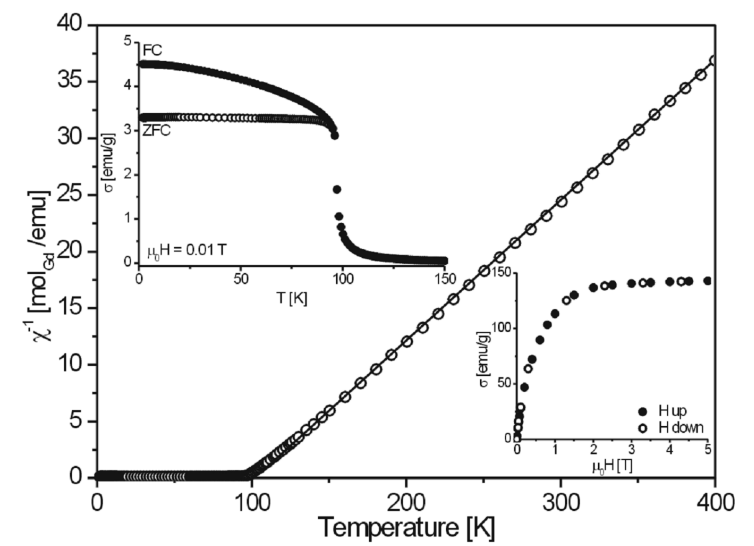

Fig. 4. Inverse magnetic susceptibility of $\mathrm{Gd}_{2} \mathrm{Cu}_{1.9} \mathrm{Co}_{0.1} \mathrm{In}$. The solid line represents the CurieWeiss fit. Insets show FC and ZFC magnetisations as well as isothermal one.

\subsection{Specific heat}

In Fig. 5 specific heat data of $\mathrm{Gd}_{2} \mathrm{Cu}_{1.9} \mathrm{Co}_{0.1}$ In are presented. For curve recorded without magnetic field the transition temperature is equal to $93.5 \mathrm{~K}$, being in agreement with XRD as well as magnetisation data. No hysteresis upon heating and cooling cycle was observed, yielding that the transition is purely of the second order. Under external magnetic field of $3 \mathrm{~T}$ the transition temperature reaches $100.0 \mathrm{~K}$. It clearly confirms ferromagnetic ordering of the sample. In order to extract magnetic part of the specific heat a non-magnetic analogue $\mathrm{Y}_{2} \mathrm{Cu}_{2} \mathrm{In}$ was studied. The data are presented in the inset to Fig. 5. The solid line in the inset represents fit of the standard formula describing electronic and lattice contributions:

$$
C_{\mathrm{ph}+\mathrm{el}}=9 R \frac{1}{1-\alpha T}\left(\frac{T}{\Theta_{\mathrm{D}}}\right)^{3} \int_{0}^{\frac{\Theta_{\mathrm{D}}}{T}} \frac{x^{4} \mathrm{e}^{x}}{\left(\mathrm{e}^{x}-1\right)^{2}} \mathrm{~d} x
$$

$$
+R \frac{1}{1-\alpha T} \sum_{i} \frac{\left(\frac{\Theta_{\mathrm{E} i}}{T}\right)^{2} \mathrm{e}^{\frac{\Theta_{\mathrm{E} i}^{T}}{T}}}{\left(\mathrm{e}^{\frac{\Theta_{\mathrm{E} i}^{T}}{T}}-1\right)^{2}}+\gamma T
$$

where $\Theta_{\mathrm{D}}$ is the Debye temperature, $\Theta_{\mathrm{E} i}$ are the Einstein temperatures, $\gamma$ is the electronic specific heat coefficient, $\alpha$ is the anharmonic coefficient and $R$ is the gas constant. The Einstein temperatures were grouped into 4 branches, each of multiplicity of 3 . The refined values for $\mathrm{Y}_{2} \mathrm{Cu}_{2} \mathrm{In}$ are as follows: $\Theta_{\mathrm{D}}=134(1) \mathrm{K}, \Theta_{\mathrm{E} 1}=123(1) \mathrm{K}$, $\Theta_{\mathrm{E} 2}=192(2) \mathrm{K}, \Theta_{\mathrm{E} 3}=225(3) \mathrm{K}, \Theta_{\mathrm{E} 4}=275(4) \mathrm{K}$, $\gamma=6 \mathrm{~mJ} /\left(\mathrm{mol} \mathrm{K}{ }^{2}\right)$ and $\alpha=1.8 \times 10^{-4} 1 / \mathrm{K}$. The above mentioned fit was a basis for estimation of non-magnetic part of $\mathrm{Gd}_{2} \mathrm{Cu}_{1.9} \mathrm{Co}_{0.1}$ In specific heat. The characteristic temperatures were rescaled according to the difference of molar masses, on the other hand, the electronic coefficient was assumed to be the same for both samples. The estimation of the anharmonic coefficient of $\mathrm{Gd}_{2} \mathrm{Cu}_{1.9} \mathrm{Co}_{0.1}$ In was made using the expansion volume coefficient as derived from XRD measurements. The estimation of non-magnetic contribution is marked with solid line in Fig. 5. The above mentioned procedure enables magnetic specific heat to be extracted.

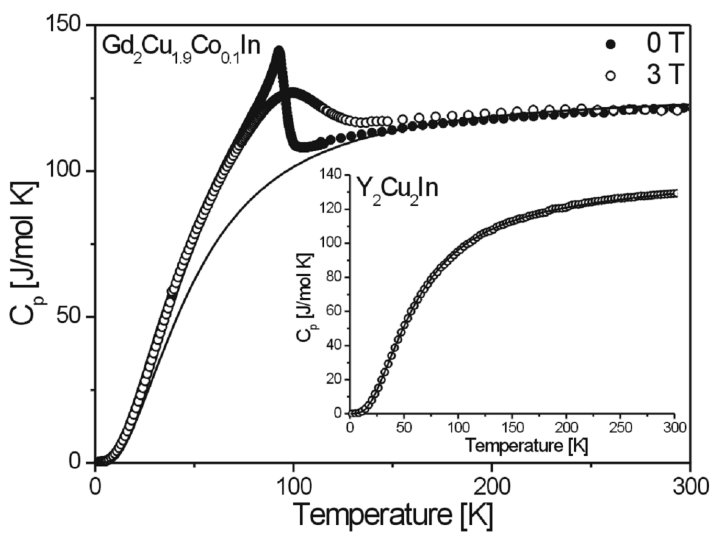

Fig. 5. Specific heat of $\mathrm{Gd}_{2} \mathrm{Cu}_{1.9} \mathrm{Co}_{0.1}$ In. Experimental points are marked with filled and open circles for external magnetic field of 0 and $3 \mathrm{~T}$, respectively. The solid line is the estimated lattice and electronic contributions. The inset shows specific heat results for non-magnetic $\mathrm{Y}_{2} \mathrm{Cu}_{2} \mathrm{In}$ reference sample.

The magnetic entropy at room temperature calculated under absence of external magnetic field is close to $32.3 \mathrm{~J} /(\mathrm{mol} \mathrm{K})$. This value is close to expected saturation $2 R \ln 8$ value. Most of the magnetic entropy is gained up to the ordering point (see Fig. 6), whereas the 


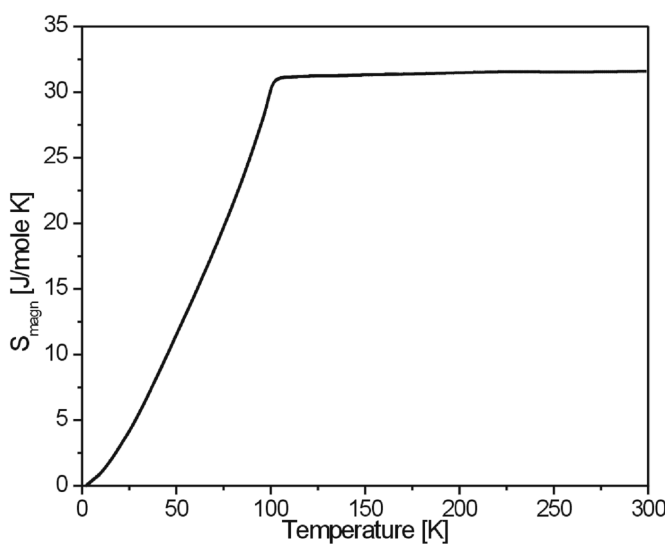

Fig. 6. Magnetic entropy of $\mathrm{Gd}_{2} \mathrm{Cu}_{1.9} \mathrm{Co}_{0.1}$ In versus temperature.

further increase of the $S_{\mathrm{magn}}(T)$ is negligibly small. This is consistent with lifting of the ${ }^{8} S_{7 / 2}$ multiplet degeneracy under the presence of the molecular field.

\section{Summary}

$\mathrm{Gd}_{2} \mathrm{Cu}_{2-x} \mathrm{Co}_{x} \mathrm{In}(x=0.1,0.2,0.3)$ samples were investigated by means of X-ray diffraction, magnetometric and calorimetric studies. It was found that only $\mathrm{Gd}_{2} \mathrm{Cu}_{1.9} \mathrm{Co}_{0.1} \mathrm{In}$ is single phased one. Further increase of Co content leads to forming impurity phase yielding lack of solubility of Co above that level. Introducing of $\mathrm{Co}$ atoms enhances ferromagnetic interactions in this sample. This is reflected in rising of ordering temperature, which is equal to $93.5 \mathrm{~K}$, in comparison to $\mathrm{Gd}_{2} \mathrm{Cu}_{2} \mathrm{In}$ compound $\left(T_{\mathrm{C}}=85.5 \mathrm{~K}\right)$. The temperature deviations of the crystal unit cell parameters correspond clearly to above mentioned magnetic properties.

\section{Acknowledgments}

This research was done within the frame of the Polish Scientific Network "Strongly correlated materials: preparation, fundamental research and applications".

\section{References}

[1] Ya.M. Kalychak, V.I. Zaremba, V.M. Baranyak, P.Yu. Zavalii, V.A. Bruskov, L.V. Sysa, O.V. Dmytrakh, Inorg. Mater. 26, 94 (1990).

[2] Ya.M. Kalychak, V.I. Zaremba, R. Pöttgen, M. Lukachuk, R.-D. Hoffmann, in: Handbook on the Physics and Chemistry of Rare Earths, Eds. K.A. Gschneidner Jr., V.K. Pecharsky, J.-C. Bünzli, Vol. 34, Elsevier, Amsterdam 2005, p. 1, Ch. 218.

[3] D. Kaczorowski, P. Rogl, K. Hiebl, Phys. Rev. B 54, 9891 (1996).

[4] S. Mock, A. Faisst, H. v. Löhneysen, Phys. Rev. B 56, 335 (1997).

[5] I.R. Fisher, Z. Islam, P.C. Canfield, J. Magn. Magn. Mater. 202, 1 (1999).

[6] N. Tsujii, H. Kitô, H. Kitazawa, G. Kido, J. Alloys Comp. 322, 74 (2001). 